\title{
Qualitative Methods 1: On current conventions in interview research
}

\author{
Russell Hitchings and Alan Latham
}

Department of Geography

UCL

Gower Street

London

WC1E 6BT

r.hitchings@,ucl.ac.uk

alan.latham@ucl.ac.uk

\section{Keywords:}

Interviews, authority, sampling, analysis, quotation, procedure.

\begin{abstract}
This report is the first in a series of three that scrutinise currently predominant ways of doing and describing qualitative research in English language human geography. Taking a sample of two hundred articles that draw on qualitative data from ten leading human geography journals, our aim is to highlight and reflect upon some of the prevailing conventions found in this field. Since interviews were by far the most widely used method in the sample, this first report considers how they feature in the work of today's human geographers. How many people do geographers speak with and what do they say about their procedures? What do they imagine their interviews to be in terms of the social occasion? And how do they present the empirical material that is thereby generated?
\end{abstract}




\section{Introduction}

When the first Progress in Human Geography qualitative methods review was published in 2002 (Crang, 2002), its author found it surprising that the journal had taken so long to turn its attention to qualitative methods. He argued that these methods were, at the time, already well established in human geography, and were perhaps even becoming something of a 'new orthodoxy' for the discipline. Since then, this trend has continued more or less unabated — so much so that qualitative approaches are no longer just the orthodoxy, but might even be said to be dominant, hegemonic even. Outside the world of Geographic Information Science, qualitative methods would seem to define human geography's direction and purpose as an empirical enterprise (Cresswell 2013; Cloke et al. 2014).

This presents a problem for any survey of the field since a survey of qualitative research effectively becomes a survey of the entire discipline. One means of making this task manageable is to consider what is new within this work. A number of the reviews that followed Crang's $(2002 ; 2003 ; 2005)$ first set, such as Davies and Dwyer (2008), Dwyer and Davies (2010), Sui and DeLyser (2012), DeLyser and Sui (2013) and Dowling et al. (2017; 2018), have taken this path. Accordingly, they have drawn our attention to the expanding suite of strategies being developed by qualitative geography researchers. And those reviews like Davies and Dwyer (2007), DeLyser and Sui (2014) and Dowling et al. (2016) that have focused on more established methods have paid particular attention to how these may be re-energised by adding additional elements. The picture that tends to follow this approach is one of a discipline in rude methodological health as we are treated to a display of intriguing innovations.

We start our series of reports by recognising that such an approach, whilst an entirely sensible way of handling the task at hand, risks over-emphasising the prevalence and potential of such methodological 'new-ness'. Furthermore, it also necessarily means that the practical research strategies of those who are not obvious methodological innovators are largely ignored. In other words, if we follow this route, the relatively silent majority of geographers who are quietly getting on with the work of capitalising on the benefits of qualitative techniques are inevitably overlooked. We point this out because, whilst there will be challenges in exploring the research and writing strategies of the everywoman and everyman of qualitative human geography, it is also the case that too full a focus on evident innovation does rather blind us to the slow creep of methodological convention in the discipline.

It is with this in mind that we take a different approach. As earlier reviews have highlighted (Crang 2002; Davies and Dwyer 2008; DeLyser and Sui 2014), a relatively small number of techniques form the core of qualitative research in human geography. It follows that, if we want to understand what is 
going on within this work, we should consider how exactly these methods are woven into the discipline. This is our ambition. Our thinking is that, by doing so, we will, firstly, be able to think afresh about the characteristics of this research and, secondly, put ourselves in a position to positively influence the 'slow creep of convention' that we introduced above. In order to do so we have taken two hundred qualitative papers from ten leading human geography journals and subjected them to a systematic evaluation in terms of how their practical methods and empirical data are presented.

Emboldened by other sympathetically critical reviews of how qualitative research currently does, and potential could, inform policy and debate elsewhere (see, for examples, Nielsen and D'haen, 2014, Snelson 2016), our reviews will explore certain human geography 'home truths' of a kind that we suspect our colleagues may sometimes mull over together in corridors but currently feel discouraged from discussing in the formal exchange of journals. And we do so not only because it is interesting to pause and reflect on how our discipline works. We do so because we worry about what the pressures under which geographers increasingly labour mean for how they do and discuss their qualitative work.

\section{The papers}

We began by selecting 10 highly cited human geography journals: Annals of the Association of American Geographers, Antipode, Area, Environment and Planning A, Geoforum, Journal of Economic Geography, Political Geography, Social and Cultural Geography, The Professional Geographer and Transactions of the Institute of British Geographers. Then we picked 20 articles from each of them. Working back from a point in the summer of 2018, we chose the most recently published articles reporting on predominantly qualitative studies. Papers that were evidently part of special issues were excluded from this process. This gave us a sizeable sample of 200 papers. These were then individually examined in terms of how they discussed their methods and drew upon their empirical material. This is, of course, an imperfect sample and there is certainly variation between these, and other, journals in how qualitative research is presented to the reader. Our intention, however, was never to compare journals - we think that 20 papers from each journal is too few for that. Nor was the intention to seek out places within the discipline where particular ways of thinking about qualitative methods have been concentrated. This exercise was about how qualitative work is generally done and discussed in English language human geography today. [1]

\section{The structure}

This first report focuses on how geographers use interviews and the second will turn to their relationship with ethnography. These were by far the two most common methods in our sample. If the aim is to reflect on current commonplaces, rather than evident innovation, they are therefore the obvious candidates for consideration. The third review is intended to explore how combining methods is discussed and to examine what their current ways of presenting qualitative research more generally 
tell us about how human geographers now see themselves. More than three quarters of our articles included the analysis of some form of interview derived material. So we now make a start by scrutinising how their interview work is presented by geographers, focusing on those papers with interviews at the heart of their analysis and which do not generally claim a wider ethnographic warrant.

\section{Procedural detail and the secret sample}

We begin by noting that, in our sample, often very little was said about why interviews were chosen. Perhaps this is not surprising. If interviews have, for many, become the taken for granted way of doing research then maybe it is no longer important to justify their use. Most described who and how many were interviewed and, in some cases, how interviewees were selected (see Figure 1). When they were specified, interviews were typically described as either 'semi-structured' or 'in-depth'; although a small number of articles used group interviews or focus groups, and a minority baldly stated that 'interviews' had been undertaken. Detail might also be offered on location, on duration, and on the general thrust of the questions; although this additional information was rarer. Though we sometimes frame our interviews as the route to an 'in-depth' appreciation of the respondent perspective, we do not now generally tell one another about how long the interviews lasted, for example. Indeed, it must be said that it was not unusual for our interview articles to omit even the most cursory procedural detail.

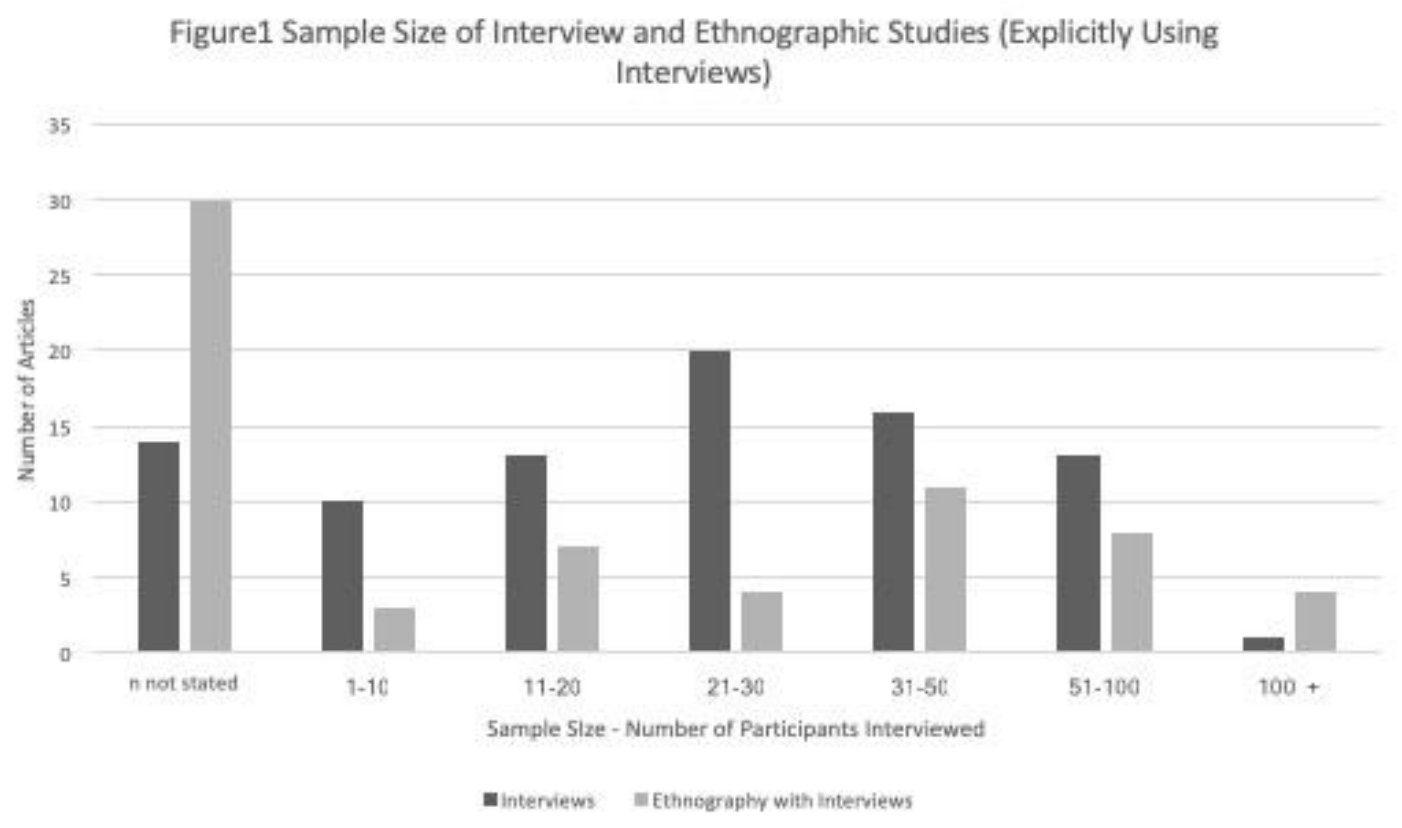

This lack of reporting on the methodological nitty gritty did not necessarily detract from the acuteness of the analysis. For example, in an engaging discussion of the enclosure of Main's open lands, Kay (2018) simply tells readers that nineteen interviews were undertaken during two months of fieldwork. Similarly, Henry and Prince (2018) in a theoretically sharp analysis of agricultural markets in New 
Zealand devote a mere five lines to how their empirical material was gathered and analysed. And, in a lively discussion of union organisation and place, Barton (2018) weaves union official interviews together with other sources without telling the reader who had been interviewed or why. Examples like these might suggest that qualitative geographers are right to be relaxed about their descriptions of method - the proof of the pudding is in the analysis and no one needs to wade through all that dull procedural detail. Nonetheless, they do raise questions about the contextual information that readers need to evaluate the robustness of the analyses with which they are presented. What, and how much, does the reader need to know about the interviewees to trust the argument that is offered up to them? And how do should they go about judging whether the right people have been spoken with?

In our review, we were also struck by the diversity of interview sample sizes - ranging from a parsimonious 4 people to a much more capacious 160. There were also instances of no numbers being provided at all. We saw no human geography convention when it comes to identifying the right quantity of respondents for our most conventional of methods. And, beyond that, very little is said about why particular samples were deemed sufficient or about their relationship to the presumably larger population from which they were picked. We are largely taking it on trust from our colleagues that, if they feel they have done enough, and they have spoken with the right people, then we should probably believe them. Whether others outside our professional cliques would agree is, of course, an open question. This puts us in mind of how elsewhere in social science, whilst hopeful appeals to 'saturation' are sometimes deployed as a means of justifying the presented sample size (O'Reilly and Parker 2013), researchers stop suspiciously often at multiples of ten (Mason, 2010); round numbers just feel like better cut off points, it would seem. Consistent with this wider climate, human geographers are also currently quite secretive with their beliefs about appropriate sampling - they keep them to themselves, even though they seem to hold quite a diversity of views on this matter.

\section{On the social occasion of the interview}

For many geographers, part of the attraction of interviews is their flexibility. It is not just that they can be effectively used to question a great variety of people, but they can also be carried out in many settings. This perhaps is obvious. But this versatility should not stop us from scrutinising how exactly these settings are taken to play into the kind of material produced by an interview. In the second of his original reviews, Crang (2003) highlighted human geographers' increasing awareness of the 'embodied' nature of field research. This meant acknowledging interviews as events that take place between two or more people - a face-to-face spoken interaction in a particular physical and social context. However, he also noted that this awareness was yet to have much impact upon how they analysed their interviews. 
Since then, as previous reviews like DeLyser and Sui (2012) and Dowling et al. (2018) have emphasised, some have started to address the physical context. We saw this occasionally in our sample too. For example, Finlay and Bowman (2017) examine how 'mobile' walking interviews open up narratival possibilities that their seated equivalents cannot. In their study, being in and moving through the contexts of their everyday lives usefully prompted respondents to reflect on concrete details of how they navigated their neighbourhood. For example, in some cases, respondents used the buildings around them to organise the narratives they were developing for the interviewer. Others have explored how brought objects, such as photographs, can enliven interviews (Bartolini et al 2017; Adams-Hutcheson 2017). Such an approach fits with human geography's enthusiasm for materiality. However, little is currently said about the social dynamics of the interview. In this sense, Crang's (2003) final observation still stands.

There were exceptions. For example, Lo et al. (2016) highlight the unusualness of the interview format in the Chinese context, Parsons and Lawreniuk (2017) explain how the presence of co-ethnic research assistants helped to put their respondents at ease, and Kuus (2016: 547) explains how, given the sensitivity of the topics involved, some interviews need to be 'non-attributable and off the record.' Still the majority of articles skip this detail. This may not be a significant problem for the relatively large number of geographers who we found speaking with those we may loosely define as 'experts', namely those who are (often professionally) taken to have a privileged insider position on the topic at hand. It is not unreasonable to expect such respondents to be relatively comfortable and practised in providing a view during an interview exchange — although, as Tokatli (2015) suggests, we might be a little more sceptical of the disinterestedness of their accounts. What we think is more surprising is that so little is generally said about how interviewers build rapport with 'non-expert' interviewees. On reading our sample of papers, many human geographers would seem to be straightforwardly strolling into people's lives, easily coaxing them into their samples, and encouraging them to be useful and engaged interlocutors. Certainly, whilst we suspect that our colleagues are often very skilled interviewers, the neophyte researcher would struggle to extract many useful pointers about how to handle the social occasion.

Perhaps — once again — this lack of detail simply reflects the established nature of the interview as method. Yet it does suggest something of a disconnect between the theoretical claims that human geographers sometimes make about their use of qualitative methods and the attention paid in their papers to practical implementation. For example, human geographers have long engaged with debates around identity and embodiment that foreground what might be called big 'P' positionality — the manner in which our personal characteristics and relative power play into the research process (England 1994; Rose 1997; Dowling 2000). This is a commonplace in disciplinary discussions of method. But in contemporary work, we are currently seeing less attention, in the written accounts that we read at least, being given to what we might call the small 'p' positionality issues that permeate our practice — how exactly we go 
about presenting ourselves to, and engaging with, our respondents and what that means for how they subsequently speak with us. We suspect that many geographers are privately thinking hard about these matters and amending their interactional strategies as required. But we are rarely getting to read about it.

\section{Current quotation cultures}

As already mentioned, those who we take to be privileged insiders are the focus of a great deal of human geography interviewing. In many such cases interview material is used to round out, extend, or add nuance to what has been gleaned from other sources. Phelps and Wood (2018) use their expert interviews to help them map out the location consultancy industry. Interview material gets them beyond the simplistic descriptions found in industry publications. Kalafski and Duggan (2016) do a similar thing in their study of Nova Scotia export firms, as do Jenkins and Tallmann (2016) in their case study of interfirm learning. And it is not just these economic geographers who use interviews in this way. Working in a more explicitly intertextual register, Belcher (2018) similarly draws on both interviews with key and a range of existing public accounts — including already published interviews with key protagonists — to examine the rationale behind the destruction of Afghani villages by the United States military. In these cases, interviewees give us the broad facts of a case or situation. In effect, they show us how things really happen. We see this in how interviewees are often seen to 'state', 'explain', 'assert', 'argue', 'sum-up' as much as they 'talk' or simply 'discuss'. In these cases, quotes are operating as a kind amulet or charm to produce authorial authority in the accounts that are presented to the reader. They demonstrate that the author(s) have indeed gone into 'the field' to access the truth of how things are happening on the ground - that they have done something more than merely collating and examining what is already available.

In these cases, quotes tend to be used sparingly. Acting as an illustration - or more accurately an instantiation — of the account (and argument) being developed, quotes are carefully chosen not to disturb the flow of the analytical narrative. So, for example, Breul and Revilla Diez (2018) in their study of a global production network restrict direct quotation to short snippets of interview text. Kivelä (2018) uses short quotes — again from experts — to back up analytical statements about the relationship between citizenship and health care provision in Finland (see also Hall 2015; Cloke and Conradson 2018). A similar effect, although created this time with more substantial interview quotes, is evident in Poon et al.'s (2018) study of Sharia finance in Malaysia. In this case, sizeable quotes are placed at key junctures to both summarise and substantiate the argument being developed. This is an exemplary illustration of the division of empirical labour implicit in expert interviews. Experts are invited to tell a story, or indeed a range of stories, that the researcher then assembles into an overall narrative, drawing on other sources and theoretical debates when necessary. Indeed it is worth noting that, for some, interview quotations are redundant — there is no need for the 'authority amulet' of the judicious quotation. In Hansen et al.'s (2016) study of the global biomass power plant, there are no quotes as interview material is rolled into a 
case study narrative. This is also the approach taken by Haikola and Anshelm (2018) in their examination of mining regulation in Sweden. House (2018) also does something similar in his Dutch study of insect based foods - the interviews are referenced, but the interpretations are presented as summaries.

Papers without quotations were few, however. And, in work focusing on those understood to be nonexperts, the importance of the direct quotation is taken to be especially important. Here the dominant convention is to use frequent longish indented quotes. Implicit in doing so is the suggestion that they not only present instantiations of the argument but also 'give voice' to the otherwise unexamined views of those being researched — often highlighting the overlooked expertise such interviewees possess. Parsons and Lawreniuk (2018), for example, in their study of Vietnamese migrants in Cambodia provide an exemplary case of using quotes to enliven and make concrete more general descriptive narratives. Whilst the experts are generally seen to state the facts of the matters as they see it, with those who are framed as non-experts by their researchers, the verbs used to preface quotes — if they are prefaced at all — have a less declarative tone. Interviewees do certainly 'explain', but they are as likely to 'reflect', or 'comment', 'tell', or 'remark.' This difference in how we engage with these two imagined categories of person is nicely illustrated by Pow's (2018) study of urban greening and planning and China — officials 'boast' or 'emphasize' whilst ordinary folk 'note', 'complain', 'query' or simply 'say'. This is presumably partly about how adept these two groups are in handling the interview experience. But it is also about how different groups are differently engaged by human geographers according to what they want from them. In both cases, however, the lived experience of the interview can end up being downplayed - either because reflecting on that might get in the way of an authoritative account or because to dwell upon this would undermine the ambition of giving others voice. We might think more about the verbs that we use to preface our quotes and we might consider other ways of telling the story of our interview studies instead of seeing quotes as a direct ticket to either authorial authority or true respondent experience.

\section{Considering the invisible interviewer}

Consistent with this last point, we also noted how little the presence of the interviewer was acknowledged in the material that is presented. In the 72 interview based articles used for this review, only 6 included the questions that prompted the presented quotes, and then this was only partially. Jones and Osborne (2018) in their study of virtual environments have quotes that include the question in a few instances, as does Maliepaard (2018) in their study of bisexuality. Loyd et al. (2018) too have questions and then answers in a couple of cases, as does Robinson (2017). Holloway and Pimlott-Wilson (2018) include a number of dialogue excerpts from group interviews in their study of children's free time - although only one includes the question posed by the interviewer. Antonsich (2018) in her study of migrants in Italy also took a more dialogical approach. These are the exceptions though; they are not the rule. 
So the interviewer as an embodied presence, to go back to Crang, is currently seldom seen in the analysis. The interviewer is more or less invisible. We think the interviewer partly disappears because of the implicit objectives in our current quotation cultures (if they are just 'telling us how it is', then we probably don't need to talk about our presence; if they are giving us a window into their world, why spoil it with concerns about how the window was opened?). It is also consistent with how, as already discussed, the social occasion of the interview is often downplayed. We have argued elsewhere that human geographers could benefit from attending to how exactly interviewees react to certain lines of questioning (Hitchings and Latham 2016). However, our survey suggests this is not currently part of how they, generally speaking, present their work. The 'voices' and 'perspectives' that current human geography interviewers seek were, in our sample at least, most often imagined to be straightforwardly there, waiting to be collected, rather than falteringly presented in ways that their own presence and ways of talking no doubt influences.

\section{Conclusion: on 'styles of interviewing' and 'doing interviews'}

The interview is a remarkably versatile research instrument. It can be used to study people in an extraordinary range of contexts. It helps us understand those who we position as experts and non-experts alike. Yet just as these attributes have made interviews incredibly popular in human geography, so many of the issues associated with using them have receded into the background hum of the discipline. This first report has sought to bring some of them back to the fore. We have found a diversity of sample sizes which are often undiscussed in terms of the implications of this selection. We have found that, though certain material features of the interview are now of interest, some important social features often pass unconsidered. And we have found that current conventions of presenting interview material may be inhibiting a fuller discussion of how exactly our interviews unfold. When we talk to colleagues who also conduct interviews we often find ourselves comparing 'styles'. However, to talk of 'styles' is to talk of personally calibrated approaches that may have idiosyncratically developed, not skills that are honed, in part, through an ongoing exchange with peers. We think that human geographers might say more in their papers about how their developing interviewing styles and practical interviewing experiences have shaped the analysis that they present. We say this because we think that doing so could be more convincing to the reader, will likely encourage others to think harder about what is happening in their own interviews, and start to build a shared licence to exchange tips and ideas as the hum of our interviewing work goes on. In our experience, when asked about methods, many of today's geographers would simply say that they individually 'do interviews'. In concluding this first report, we suggest that this taken for granted quality may be standing in the way of an enriching discussion of how we collectively 'do' them better.

\section{Endnotes}

[1] It is important to acknowledge how certain journals were crucial in the establishment and disciplinary legitimation of qualitative methods. Journals such as Gender, Place and Culture and later Social and Cultural Geography, and Emotion Space and Society 
were, from their foundation, predominantly qualitative in orientation - underlining and advancing the idea that qualitative research is not a straightforward supplement to quantitative, or indeed theoretically oriented, approaches.

\section{Acknowledgements}

We would like to thank the editors, Noel Castree and Nina Laurie, for encouraging us to undertake these reviews and for helping us to define our contribution. Thanks also to all the students, past and present, on our MSc human geography methods course Figuring People Out for pushing us to think harder about what we are doing when we do qualitative research.

\section{References}

Adams-Hutcheson, G. (2017) Farming in the troposphere: drawing together affective atmospheres and elemental geographies. Social and Cultural Geography. doi.org/10.1080/14649365.2017.1406982.

Antonsich, M. (2018) Living in diversity: Going beyond the local/national divide. Political Geography. 63: $1-9$.

Bartolini, N., MacKian, S., and Pile, S. (2018) Talking with the dead: Spirit mediumship, affect and embodiment in Stoke - on - Trent. Transactions of the Institute of British Geographers. 43(2): 170-183.

Barton, R. (2018) "Our Tarkine, Our Future": The Australian Workers Union use of narratives around place and community in west and north west Tasmania, Australia. Antipode. 50(1): 41-60.

Belcher, O. (2018) Anatomy of a village razing: Counterinsurgency, violence, and securing the intimate in Afghanistan. Political Geography. 62: 94-105.

Breul, M., and Revilla Diez, J. (2018) An intermediate step to resource peripheries: The strategic coupling of gateway cities in the upstream oil and gas GPN. Geoforum. 92: 9-17.

Cloke, P. and Conradson, D. (2018) Transitional organisations, affective atmospheres and new forms of being - in - common: Post - disaster recovery in Christchurch, New Zealand. Transactions of the Institute of British Geographers. 43(3):360-376.

Cloke, P., Crang, P. and Goodwin, M. (eds) (2014) Introducing Human Geographies. New York: Routledge.

Crang, M. (2002) Qualitative methods: the new orthodoxy? Progress in Human Geography. 26(5): 647-655.

Crang, M. (2003) Qualitative methods: touchy, feely, look-see?. Progress in Human Geography. 27(4): 494-504. 
Crang, M. (2005) Qualitative methods: there is nothing outside the text?. Progress in Human Geography. 29(2): 225-233.

Cresswell, T. (2013) Geographic Thought: A Critical Introduction. Oxford: Wiley-Blackwell.

Davies, G., and Dwyer, C. (2007) Qualitative methods: are you enchanted or are you alienated?. Progress in Human Geography. 31(2): 257-266.

Davies, G., and Dwyer, C. (2008) Qualitative methods II: minding the gap. Progress in Human Geography. 32(3): 399-406.

DeLyser, D., and Sui, D. (2013) Crossing the qualitative-quantitative divide II: Inventive approaches to big data, mobile methods, and rhythmanalysis. Progress in Human Geography. 37(2): 293-305.

DeLyser, D., and Sui, D. (2014) Crossing the qualitative-quantitative chasm III: Enduring methods, open geography, participatory research, and the fourth paradigm. Progress in Human Geography. 38(2): 294-307.

Dowling, R. (2000). Power, subjectivity and ethics in qualitative research. In: Hay, I (ed) Qualitative Research Methods in Human Geography. Sydney: Oxford University.

Dowling, R., Lloyd, K., and Suchet-Pearson, S. (2016) Qualitative methods I: Enriching the interview. Progress in Human Geography. 40(5): 679-686.

Dowling, R., Lloyd, K., and Suchet-Pearson, S. (2017) Qualitative methods II: 'More-than-human' methodologies and/in praxis. Progress in Human Geography. 41(6): 823-831.

Dowling, R., Lloyd, K., and Suchet-Pearson, S. (2018) Qualitative methods III: Experimenting, picturing, sensing. Progress in Human Geography, 42(5): 779-788.

Dwyer, C., and Davies, G. (2010). Qualitative methods III: animating archives, artful interventions and online environments. Progress in Human Geography. 34(1): 88-97.

England, K. (1994). Getting personal: Reflexivity, positionality, and feminist research. The Professional Geographer. 46(1): 80-89. 
Finlay, J. and Bowman, J. (2017) Geographies on the Move: A Practical and Theoretical Approach to the Mobile Interview. The Professional Geographer, 69(2): 263-274.

Haikola, S., and Anshelm, J. (2018) State regulation of mining in a post-fordist economy: Local vulnerability in the shadow of hierarchy. Political Geography. 62: 68-78.

Hall, S. (2015) Financial networks and the globalization of transnational corporations: the case of educational services. Journal of Economic Geography. 15: 539-559.

Hansen, U., Fold, N. and Hansen, T (2016) Upgrading to lead firm position via international acquisition: learning from the global biomass power plant industry. Journal of Economic Geography. 16: $131-153$.

Henry, M., and Prince, R. (2018).Agriculturalizing finance? Data assemblages and derivatives markets in small-town New Zealand. Environment and Planning A: Economy and Space. 50(5): 989-1007.

Hitchings, R. and Latham, A. (2016) Indoor versus outdoor running: understanding how recreational exercise comes to inhabit environments through practitioner talk. Transactions of the Institute of British Geographers. 41(4): 503-514.

Holloway, S., and Pimlott-Wilson, H. (2018) Title Reconceptualising play: Balancing childcare, extracurricular activities and free play in contemporary childhoods. Transactions of the Institute of British Geographers. 43(3): 420-434.

House, J. (2018) Insects are not 'the new sushi': theories of practice and the acceptance of novel foods. Social and Cultural Geography. DOI 10.1080/14649365.2018.1440320

Jenkins, M. and Tallman, S. (2016) The geography of learning: Ferrari gestione sportiva 1929-2008. Journal of Economic Geography. 16: 447-470.

Jones, P. and Osborne, T. (2018) Analysing virtual landscapes using postmemory. Social and Cultural Geography. DOI: 10.1080/14649365.2018.1474378

Kalafsky, R. and Duggan, D. (2016) Overcoming trade impediments: Considering SME exporters from Nova Scotia, The Professional Geographer. 68(4): 613-623. 
Kay, K (2017) Rural Rentierism and the Financial Enclosure of Maine's Open Lands Tradition. Annals of the American Association of Geographers. 107(6): 1407-1423.

Kivelä, S. (2018) Active citizenship, public sector and the markets: Freedom of choice as a state project in health care. Geoforum. 91: 160-169.

Kuus, M. (2016) “To Understand the Place”: Geographical Knowledge and Diplomatic Practice. The Professional Geographer. 68(4): 546-553.

Lo, A., Cheung, L., Lee, A. and Xu, B. (2016) Confidence and trust in public institution natural hazards management: Case studies in urban and rural China. The Professional Geographer. 68(3): 475-484.

Loyd, J., Ehrkamp, P., and Secor, A. (2018). A geopolitics of trauma: Refugee administration and protracted uncertainty in Turkey. Transactions of the Institute of British Geographers. 43(3): 377-389.

Maliepaard, E. (2018), Spaces with a bisexual appearance: Reconceptualizing bisexual space(s) through a study of bisexual practices in the Netherlands. Social and Cultural Geography. DOI 10.1080/14649365.2018.1454979

Mason, M. (2010). Sample size and saturation in PhD studies using qualitative interviews. Forum: qualitative social research (Vol. 11, No. 3).

Nielsen, J. and D'haen, S. (2014) Asking about climate change: Reflections on methodology in qualitative climate change research published in Global Environmental Change since 2000. Global Environmental Change. 24: 402-409.

O’Reilly, M., and Parker, N. (2013) ‘Unsatisfactory Saturation’: a critical exploration of the notion of saturated sample sizes in qualitative research. Qualitative Research. 13(2): 190-197.

Parsons, L., and Lawreniuk, S. (2018) Seeing like the stateless: Documentation and the mobilities of liminal citizenship in Cambodia. Political Geography. 62: 1-11.

Phelps, N. and Wood, A. (2018) Promoting the global economy: The uneven development of the location consulting industry. Environment and Planning A. 50(6): 1336-1354. 
Poon, J., Pollard, J. and Chow Y. W. (2018) Resetting neoliberal values: Lawmaking in Malaysia's Islamic finance. Annals of the American Association of Geographers. 108(5): 1442-1456.

Pow C. (2018) Building a harmonious society through greening: Ecological civilization and aesthetic governmentality in China. Annals of the American Association of Geographers. 108(3): 864-883.

Robinson, P. (2018) Learning spaces in the countryside: university students and the Harper assemblage. Area. 50(2): 274-282.

Rose, G. (1997) Situating knowledges: positionality, reflexivities and other tactics. Progress in Human Geography. 21(3): 305-320.

Snelson, C. 2016. Qualitative and Mixed Methods Social Media Research: A Review of the Literature. International Journal of Qualitative Methods. 15: 1-15.

Sui, D., and DeLyser, D. (2012) Crossing the qualitative-quantitative chasm I: Hybrid geographies, the spatial turn, and volunteered geographic information (VGI). Progress in Human Geography. 36(1): 111-124.

Tokatli, N. (2015) Single-firm case studies in economic geography: some methodological reflections on the case of Zara. Journal of Economic Geography. 15: 631-647. 